\title{
Digoxin-induced retinal degeneration depends on rhodopsin
}

\author{
Britta Landfried ${ }^{1}$, Marijana Samardzija ${ }^{1}$, Maya Barben ${ }^{1,2}$, Christian Schori ${ }^{1,3}$, Katrin Klee $^{1,3}$, Federica Storti ${ }^{1}$ and Christian Grimm ${ }^{\star, 1,2,3}$
}

$\mathrm{Na}$,K-ATPases are energy consuming ion pumps that are required for maintaining ion homeostasis in most cells. In the retina, $\mathrm{Na}$,K-ATPases are especially important to sustain the dark current in photoreceptor cells needed for rapid hyperpolarization of rods and cones in light. Cardiac glycosides like digoxin inhibit the activity of $\mathrm{Na}$,K-ATPases by targeting their catalytic alpha subunits. This leads to a disturbed ion balance, which can affect cellular function and survival. Here we show that the treatment of wild-type mice with digoxin leads to severe retinal degeneration and loss of vision. Digoxin induced cell death specifically in photoreceptor cells with no or only minor effects in other retinal cell types. Photoreceptor-specific cytotoxicity depended on the presence of bleachable rhodopsin. Photoreceptors of Rpe65 knockouts, which have no measurable rhodopsin and photoreceptors of $R$ pe $65^{R 91 W}$ mice that have $<10 \%$ of the rhodopsin found in retinas of wild-type mice were not sensitive to digoxin treatment. Similarly, cones in the all-cone retina of $\mathrm{Nrl}$ knockout mice were also not affected. Digoxin induced expression of several genes involved in stress signaling and inflammation. It also activated proteins such as ERK1/2, AKT, STAT1, STAT3 and CASP1 during a period of up to 10 days after treatment. Activation of signaling genes and proteins, as well as the dependency on bleachable rhodopsin resembles mechanisms of light-induced photoreceptor degeneration. Digoxin-mediated photoreceptor cell death may thus be used as an inducible model system to study molecular mechanisms of retinal degeneration.

Cell Death and Disease (2017) 8, e2670; doi:10.1038/cddis.2017.94; published online 16 March 2017

Retinal degenerative diseases like retinitis pigmentosa or age-related macular degeneration (AMD) lead to strong visual impairment or blindness and have a high socio-economic impact. Although they affect a large number of patients and the incidence is expected to increase during the next decades especially for AMD, ${ }^{1}$ an efficient treatment option is still an unmet medical need. A main reason for the lack of therapies is the insufficient understanding of the pathophysiological mechanisms responsible for disease initiation and progression even though many animal models have been developed and studied. ${ }^{2}$ These models are either based on genetic manipulations or on the application of toxic stimuli such as light $^{3}$ or $\mathrm{N}$-methyl-N-nitrosourea (MNU) ${ }^{4}$ and may give insights into specific aspects of disease pathology. Nevertheless, additional models based on different molecules or pathways are desirable to further broaden approaches and experimental possibilities for investigations.

Cardiac glycosides like digoxin or ouabain inhibit $\mathrm{Na}, \mathrm{K}-\mathrm{ATP}$ ases and are traditionally used to treat atrial fibrillation and atrial flutter. ${ }^{5}$ Owing to their cytotoxic properties, they are also discussed as possible anticancer agents. ${ }^{6}$ Although different cardiac glycosides have slightly different specificities for different isoforms of the Na,K-ATPases, ${ }^{7}$ their inhibitory action on the ion pump causes increased intracellular $\mathrm{Na}^{+}$and $\mathrm{Ca}^{2+}$ and decreased $\mathrm{K}^{+}$concentrations. ${ }^{8}$ This disturbance of the ion homeostasis may affect cellular function and viability. As cardiac glycosides inhibit $\mathrm{Na}, \mathrm{K}-\mathrm{ATP}$ ases in all tissues including the retina, it is not surprising that several reports suggest an effect of digoxin on vision, with strongest disturbances of the cone pathway. 9,10 $^{10}$

$\mathrm{Na}, \mathrm{K}$-ATPases are heterodimers, composed of an alphaand a beta-subunit. ${ }^{11}$ In addition, they can be regulated by an auxiliary FXYD protein. ${ }^{12,13}$ Cardiac glycosides target primarily the catalytic alpha subunit of the Na,K-ATPase. ${ }^{14,15}$ Four alpha subunits have been identified that are encoded by different genes (Atp1a1-Atp1a4) and show tissue-specific expression. Whereas $a 1$ is quite ubiquitously expressed in many tissues including the retina, $a 2$ and $a 3$ show a more specific pattern and have also been found in brain and retina. ${ }^{16}$ Whereas $a 2$ may be specific for Müller glia cells, $a 3$ has been identified on all retinal neurons with particularly strong expression in photoreceptors, but not on Müller cells or the retinal pigment epithelium (RPE). ${ }^{17}$ In contrast, $a 4$ may be restricted to testis where it is important for sperm maturation. ${ }^{18}$

Since digoxin shows some preference for $a 2$ and $a 3$ isoforms ${ }^{7}$ it may affect activity of $\mathrm{Na}, \mathrm{K}$-ATPases in the retina. Reports of patients describing visual disturbances, blurred vision, central scotomas or seeing yellowish ${ }^{19}$ after digoxin treatment support this conclusion. Similarly, studies in monkeys demonstrated that digoxin can affect function especially of the cone system, ${ }^{10}$ and a recent report showed that treating mice with high doses of digoxin causes retinal degeneration. ${ }^{20}$ Thus, we investigated the effect of digoxin on the mouse retina and focused on its potential cytotoxicity for photoreceptor cells in different wild type and transgenic mouse lines. We established a treatment protocol that induces severe

\footnotetext{
${ }^{1}$ Lab for Retinal Cell Biology, Department of Ophthalmology, University of Zürich, Zürich, Switzerland; ${ }^{2}$ Neuroscience Center Zürich (ZNZ), University of Zürich, Zürich, Switzerland and ${ }^{3}$ Center for Integrative Human Physiology (ZIHP), University of Zürich, Zürich, Switzerland

${ }^{*}$ Corresponding author: C Grimm, Lab for Retinal Cell Biology, Department of Ophthalmology, University of Zürich, Wagistrasse 14, Schlieren, CH 8952, Switzerland. Tel: +41 44556 3001; Fax: +41 44556 3999; E-mail: cgrimm@opht.uzh.ch Received 20.11.16; revised 09.2.17; accepted 10.2.17; Edited by A Verkhrtasky
} 
loss of photoreceptors and propose that digoxin-mediated photoreceptor cell death may be used as a novel model to study mechanisms of retinal degeneration.

\section{Results}

Digoxin-induced retinal degeneration. To characterize the morphological, functional and molecular response to digoxin treatment, we titrated the amount of digoxin and the number of intraperitoneal (ip) injections needed for the induction of photoreceptor degeneration in C57BL/6 mice. In a first set of experiments, we used a dose of $2 \mathrm{mg} / \mathrm{kg}$ that was reported by Hinshaw et al. ${ }^{20}$ to cause photoreceptor degeneration after 5 (least number of injections reported) or more intraperitoneal injections. This dose induced severe retinal degeneration already after three daily ip injections whereas one and two injections did not noticeably alter retinal morphology (Figure 1a). Although the extent of degeneration was slightly variable, cell death was largely restricted to the outer nuclear layer (ONL) as almost no TUNEL-positive cells were detected in other retinal layers (Figure 1a). Three injections of a lower dose (up to $1 \mathrm{mg} / \mathrm{kg}$ ) did not cause degeneration (Figure $1 \mathrm{~b}$ ). Consequently, a treatment protocol of one digoxin injection on each of three consecutive days at a dose of $2 \mathrm{mg} / \mathrm{kg}$ was established and used for most of the following experiments. Although strong morphological damage was observed at 2 days, we detected pyknotic nuclei in the ONL as early as 1 day after the last injection (Figure 1c, white arrowheads). This was followed by a complete disruption of the outer and inner segments and loss of photoreceptors in the central retina between 2 and 10 days, the last time point analyzed (Figure 1c). Degeneration was accompanied by macrophage infiltration to the subretinal space (Figure 1c, black arrow). Loss of photoreceptor cells was most significant in the central retina whereas the retinal periphery was largely spared (Figures 2a and 6f). Consequences of digoxin treatment were also followed in vivo by fundus photography and optical coherence tomography (OCT) at 9 days after treatment (Figure 2b). Injections of digoxin caused the fundus to appear more intensely pigmented, probably due to the thinned retinal tissue. OCT images confirmed severe thinning of the ONL in digoxin-treated but not in control mice. Some regions of the retina in digoxin-treated mice were detached from the RPE suggesting potential subretinal fluid accumulation (Figure 2b).

TUNEL staining (Figure 1a) suggested that the toxic effect of digoxin was largely restricted to photoreceptor cells. This conclusion was further supported by immunofluorescence staining of retinal cell markers in retinas at 10 days after digoxin or PBS treatment. Distribution of peanut agglutinin (PNA) and G-protein subunit alpha transducin 1 (GNAT1) showed that both cones and rods were directly or indirectly affected by digoxin (Figure 3a). In contrast, normal distribution of visual system homeobox 2 (VSX2), pou domain, class4, transcription factor 1 (POU4F1), calbindin 1 (CALB1) and calretinin (CR) suggested that bipolar cells, ganglion cells, horizontal cells and amacrine cells, respectively, were largely unaffected (Figures $3 \mathrm{~b}$ and c). Nevertheless, digoxin induced degeneration of photoreceptors activated Müller glia cells as indicated by increased GFAP staining and stimulated resident IBA1-positive microglia and/or macrophages to migrate to the subretinal space (Figure 3d).

As expected, digoxin-induced loss of photoreceptors affected scotopic and photopic retinal function at 10 days after treatment. Scotopic and photopic b-wave, as well as scotopic a-wave amplitudes were reduced indicating loss of function (Figures $4 a$ and c). Even though morphological and immunofluorescence analyses suggested that digoxin toxicity was confined to photoreceptors in the outer retina, cells of the inner retina may have been affected functionally. ERG recordings one day after two digoxin injections $(2 \mathrm{mg} / \mathrm{kg})$, a treatment that did not induce photoreceptor degeneration (Figure 1a), showed prolonged responses at low light intensities, a reduction of the maximal $b$-wave amplitudes and strongly reduced oscillatory potentials for both the scotopic and the photopic ERG (Figures $4 \mathrm{~b}$ and $\mathrm{c}$ ). These observations resemble functional consequences reported for ocular ischemia ${ }^{21}$ that is characterized by a reduced supply of oxygen to the inner retina. ${ }^{22}$ Interestingly, digoxin can reduce heart rate re $^{23}$ and cause vasoconstriction of peripheral arteries, ${ }^{24}$ and may thus potentially lead to a reduced blood flow in peripheral organs including the retina. Clearly, further experimentation is required to evaluate the influence of digoxin on retinal function.

Molecular signaling. Digoxin inhibits Na,K-ATPases ${ }^{25}$ through interaction with the regulatory alpha subunits, with a preference for $a 2$ and $a 3$ (ref. 26) (see 'Introduction' section). As a4 was reported to be specifically expressed in testis, ${ }^{18}$ we focused on $a 1, a 2$ and $a 3$ for our analysis. As reported before ${ }^{17}$ all three alpha subunits were expressed in the normal mouse retina (Figure 5a). Treatment with digoxin increased expression of Atp $1 a 1$ at $1 \mathrm{~d}$ and $10 \mathrm{~d}$, did not affect Atp 1a2 and reduced the expression of Atp1a3 (Figure 5a). As a3 shows a strong expression in photoreceptors whereas a1 and $a 2$ may be expressed preferentially by other retinal cells, ${ }^{17}$ downregulation of Atp 1 a3 expression may reflect the degenerative process with photoreceptor injury and death. In addition, digoxin treatment induced retinal expression of several genes involved in stress signaling such as endothelin-2 (Edn2), fibroblast growth factor 2 (Fgf2) and glial fibrillary acidic protein (Gfap), in degeneration and inflammation including caspase 1 (Casp1) and tumor necrosis factor alpha (Tnf), and in oxidative stress like heme oxygenase 1 (Hmox1; Figure 5b). Peak of activation was at 2 days after the last digoxin injection. Expression levels returned to basal levels at 10 days after injections suggesting a general recovery from treatment. This interpretation was supported by the pattern of protein activation (Figure $5 \mathrm{c}$ ). Phosphorylation of the signaling proteins extracellular signal regulated kinase (ERK), protein kinase $B$ (alias AKT), signal transducer and activator of transcription 1 (STAT1) and of STAT3 peaked at 1 and 2 days after treatment, reaching basal levels thereafter. Interestingly, we consistently observed that levels of pERK $1 / 2$ were strongly reduced at 5 and 10 days post treatment. The reason and the functional consequences for such a reduced pERK signaling are unknown and remain to be evaluated. It has been reported that digoxin increases phosphorylation of protein kinase 

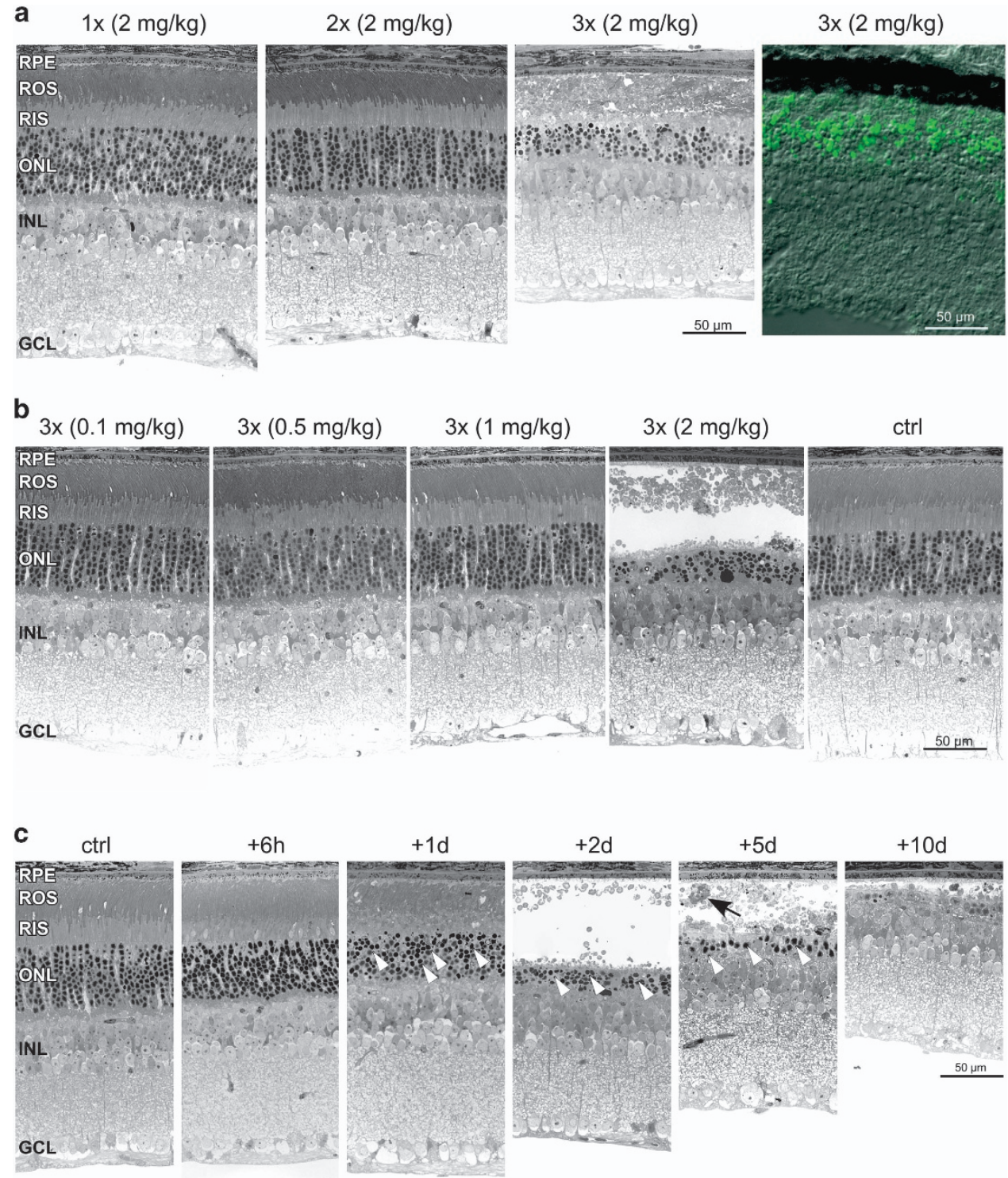

$+10 d$

Figure 1 Digoxin-induced retinal degeneration. (a) Retinal morphology of mice at 2 days after the last of 1,2 or 3 injections of $2 \mathrm{mg} / \mathrm{kg}$ digoxin as indicated. TUNEL staining (right panel) at 1 day after the last of 3 injections of $2 \mathrm{mg} / \mathrm{kg}$ digoxin. (b) Retinal morphology of mice at 2 days after the last of 3 injections of $0.1,0.5,1 \mathrm{or} 2 \mathrm{mg} / \mathrm{kg}$ digoxin as indicated. (c) Retinal morphology of mice at $6 \mathrm{~h}, 1 \mathrm{~d}, 2 \mathrm{~d}, 5 \mathrm{~d}$ and $10 \mathrm{~d}$ after the last of 3 injections of $2 \mathrm{mg} / \mathrm{kg}$ digoxin as indicated. $N=3$. Black arrow, macrophage; Ctrl, PBSinjected control mice; GCL, ganglion cell layer; INL, inner nuclear layer; ONL, outer nuclear layer; RPE, retinal pigment epithelium; ROS, rod outer segments; RIS, rod inner segments; Scale bars, $50 \mu \mathrm{m}$; white arrowheads: pyknotic nuclei

AMP-activated catalytic subunit alpha 1 (AMPK) and may thus affect energy levels in cells. ${ }^{27}$ In retinas of digoxintreated mice, however, pAMPK levels remained constant with a slight decrease by 5 and 10 days after the last injection. In contrast, proteins indicating reactive gliosis and degeneration (GFAP and CASP1) were induced primarily between 2 and 10 days, and thus after the initial signaling events. A late response of CASP1 was also observed in other models of retinal degeneration. ${ }^{28}$ As in the light damage model and during degeneration in the VPP mouse model for inherited degeneration, ${ }^{28}$ we did not detect $\mathrm{P} 10$ or P20 cleaved forms of CASP1 (not shown). Levels of the p85 regulatory subunit of $\mathrm{PI} 3 \mathrm{~K}$ remained at constant levels, even though this protein is known to be involved in Na,K-ATPase signaling. ${ }^{29,30}$ Levels of hypoxia-inducible factor $1 \mathrm{~A}$ (HIF1A) were bi-phasic with an initial decline at $1 \mathrm{~d}$, followed by an increase until $10 \mathrm{~d}$ post treatment. Although ERG data (Figure 4) may indicate that digoxin application resulted in a condition resembling retinal ischemia, we did not detect increased HIF1A levels shortly after treatment presumably because digoxin can inhibit HIF1A, as reported by others. ${ }^{31,32}$ Only after clearance of digoxin, HIF1A levels may increase and reach the levels detected between 2 and 10 days. However, this bi-phasic appearance of HIF1A was not reflected by corresponding mRNA levels of HIF1 target genes suggesting that HIF1 activity was not strongly affected by digoxin (data not shown). 


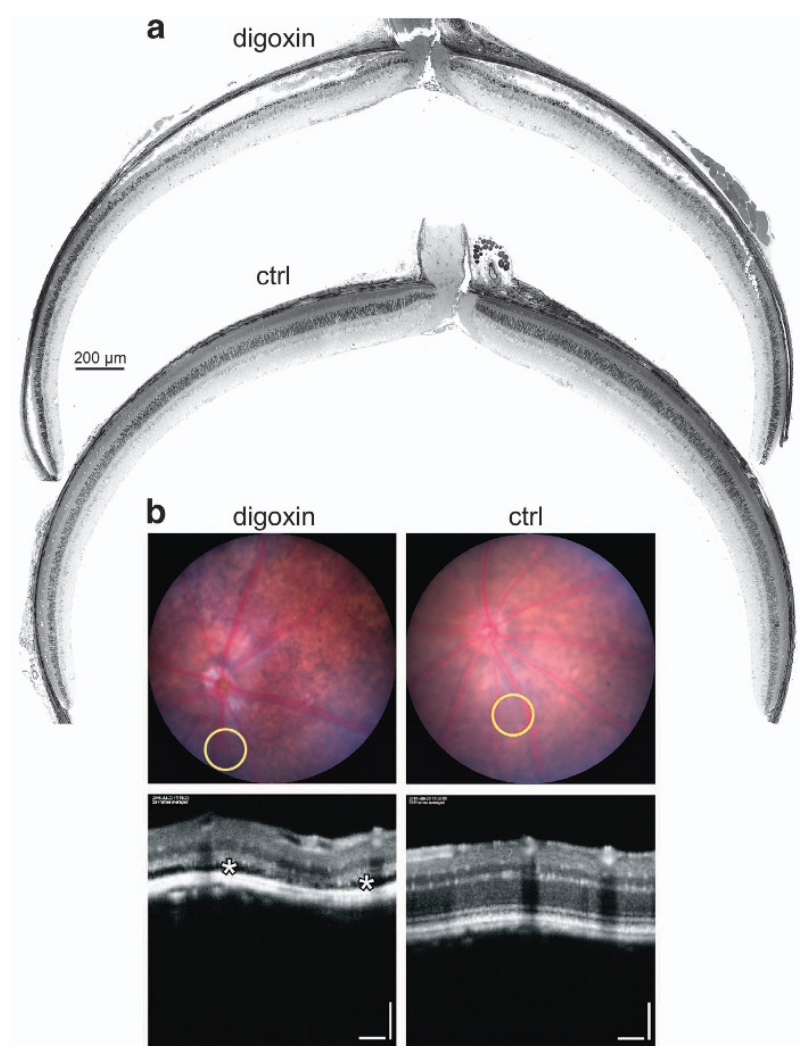

Figure 2 Geographic extent and in vivo imaging of digoxin-induced retinal degeneration. (a) Dorsoventral retinal panoramas of digoxin- (digoxin, top) or PBStreated (ctrl, bottom) mice at 2 days after the last of 3 injections of $2 \mathrm{mg} / \mathrm{kg}$ digoxin. Scale bar, $200 \mu \mathrm{m} . N=3$. (b) Fundus (top) and OCT (bottom) images of digoxin (digoxin, left) and untreated (ctrl, right) mice at 9 days after the last of 3 injections of $2 \mathrm{mg} / \mathrm{kg}$ digoxin. Yellow circles indicate the position of the corresponding OCT images. White asterisks mark subretinal fluid accumulation. Scale bar, $100 \mu \mathrm{m} . N=2$

Dependency on rhodopsin. As digoxin-induced retinal degeneration might be used as a model to study degenerative processes, we tested the susceptibility of different mouse strains to degeneration. Similar to C57BL/6 mice, photoreceptors of $129 S 6$ wild-type mice were strongly damaged 2 days after the last injection of digoxin $(3 \times 2 \mathrm{mg} / \mathrm{kg}$; Figure $6 \mathrm{a})$. Surprisingly, however, photoreceptors of Rpe $65^{R 91 W}$ mice on a $129 S 6$ genetic background were completely insensitive to digoxin treatment (Figure 6b). Similarly, photoreceptors of Rpe65 ${ }^{-1}$ mice that are on a C57BL/6 background were also not damaged (Figure $6 \mathrm{c}$ ). Common to these two mouse strains is the reduced amount (in $R p e 65^{R 91 W}$ ) or lack (in $R p e 65^{-1}$ ) of bleachable rhodopsin caused by the low activity or complete absence, respectively, of RPE65 in the RPE. ${ }^{33}$ Furthermore, cone photoreceptors of $\mathrm{Nr}^{-1}$ mice did also not degenerate after digoxin application (Figure 6d). These data suggest that rhodopsin is required for digoxin-induced photoreceptor degeneration and that cones may be insensitive to digoxin cytotoxicity. Therefore, the influence on cone morphology (Figure 3 ) and function (Figures $4 \mathrm{a}$ and $\mathrm{b}$ ) observed in C57BL/6 mice might have been indirectly caused by the degeneration of rods. Lack of digoxin sensitivity was not due to reduced expression of Atp1a genes in retinas of the respective strains since Atp1a1 and Atp1a2 were similarly expressed in all strains tested. Although the protected transgenic mice
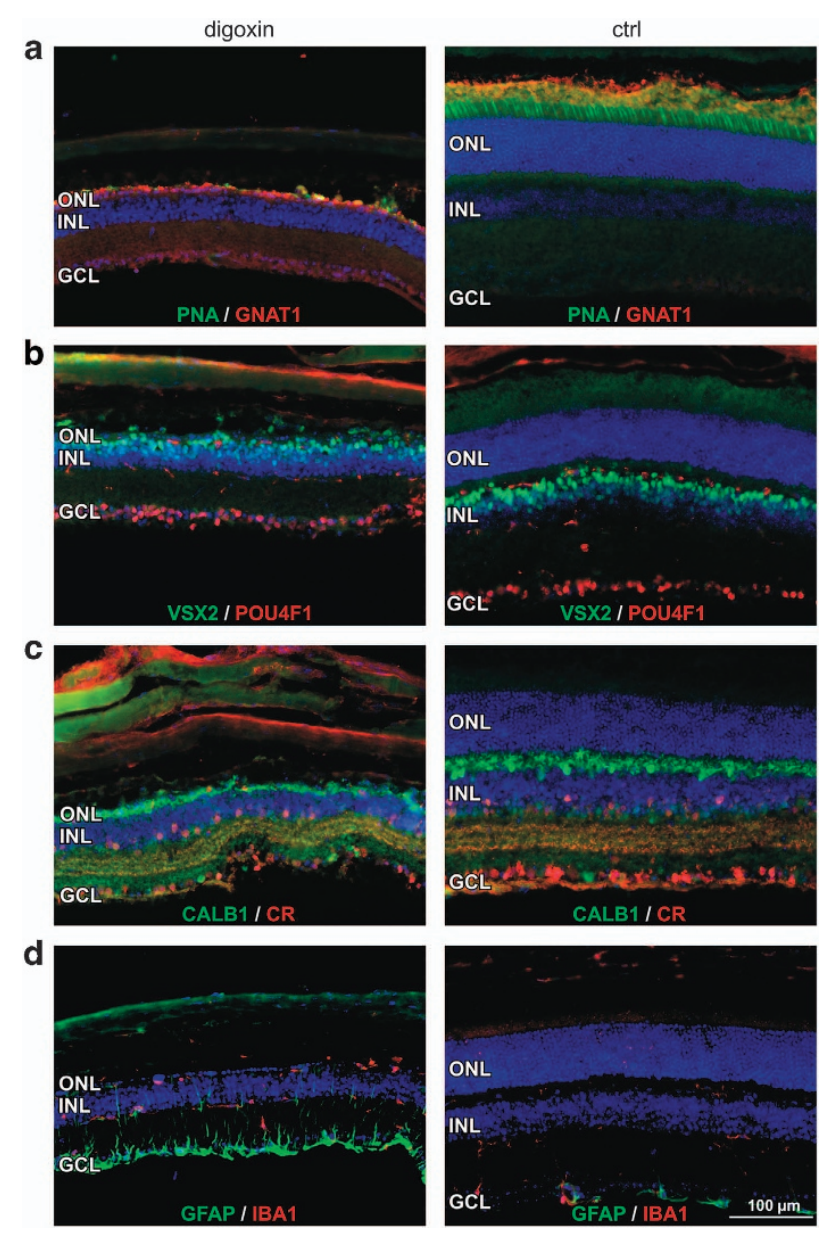

Figure 3 Localization of retinal cell markers after digoxin treatment. Retinal sections of mice at 10 days after the last of 3 injections of $2 \mathrm{mg} / \mathrm{kg}$ digoxin (left) or PBS (ctrl, right) were stained with PNA (green) and antibodies against GNAT1 (red) (a), VSX2 (green) and POU4F1 (red) (b), CALB1 (green) and CR (red) (c) and GFAP (green) and IBA1 (red) (d). Ctrl, PBS-injected control mice; GCL, ganglion cell layer; INL, inner nuclear layer; ONL, outer nuclear layer; RPE, retinal pigment epithelium; ROS, rod outer segments; RIS, rod inner segments; Scale bars, $100 \mu \mathrm{m} . N=3$

expressed Atp1a3 at lower levels than C57BL/6 mice, expression was nevertheless similar to the susceptible mice of the 12956 strain (Figure 6e).

As degeneration depended on rhodopsin, we tested whether increased photon absorption would accelerate the degenerative process in C57BL/6 mice. However, mice that were kept in cyclic light during treatment and during the 2-day post-treatment period (light) were damaged similarly to mice that were kept in constant darkness after the last digoxin injection (dark). The central retinal region showed similar levels of pyknotic photoreceptor nuclei and disrupted inner and outer segments whereas the peripheral retinal areas were spared independently of the light condition (Figure 6f).

\section{Discussion}

We showed that daily intraperitoneal injections of $2 \mathrm{mg} / \mathrm{kg}$ digoxin on 3 consecutive days induced severe retinal 
a
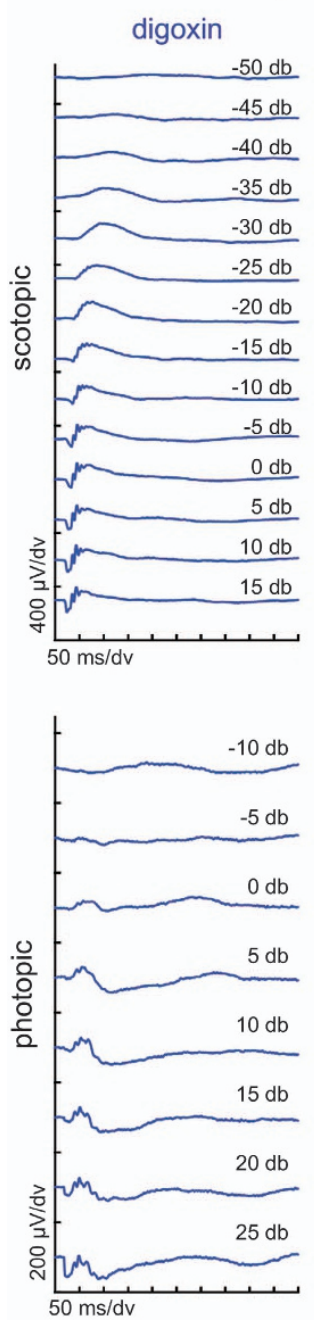

b $2 \times$ digoxin +1 day
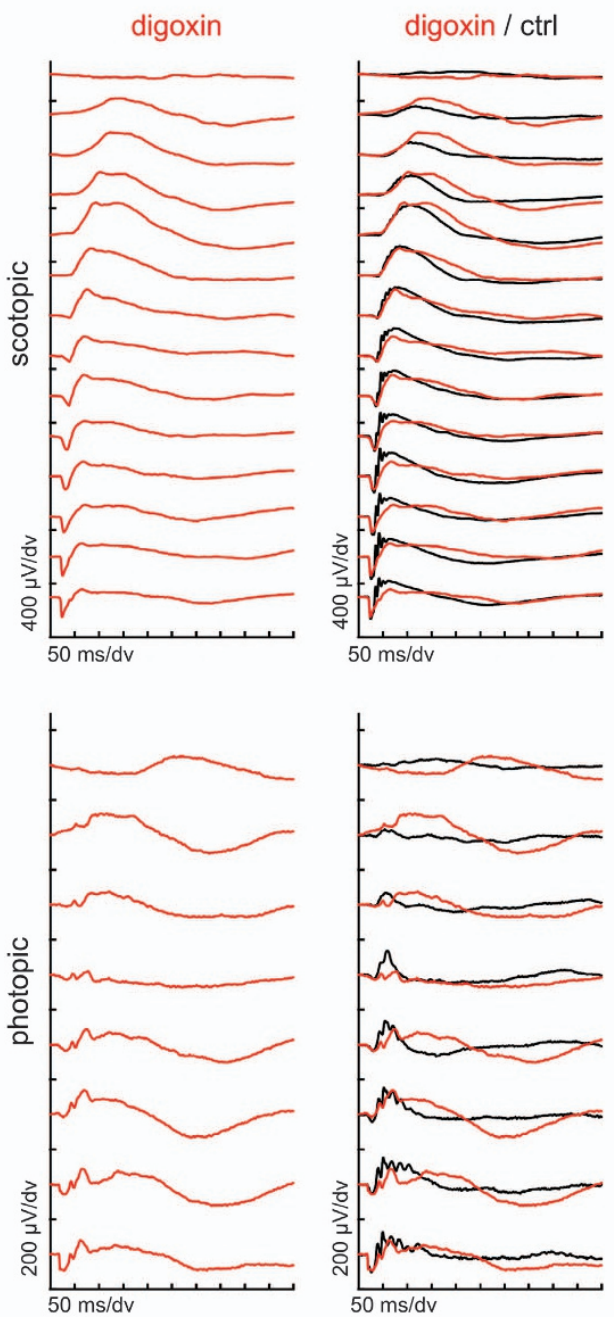

C
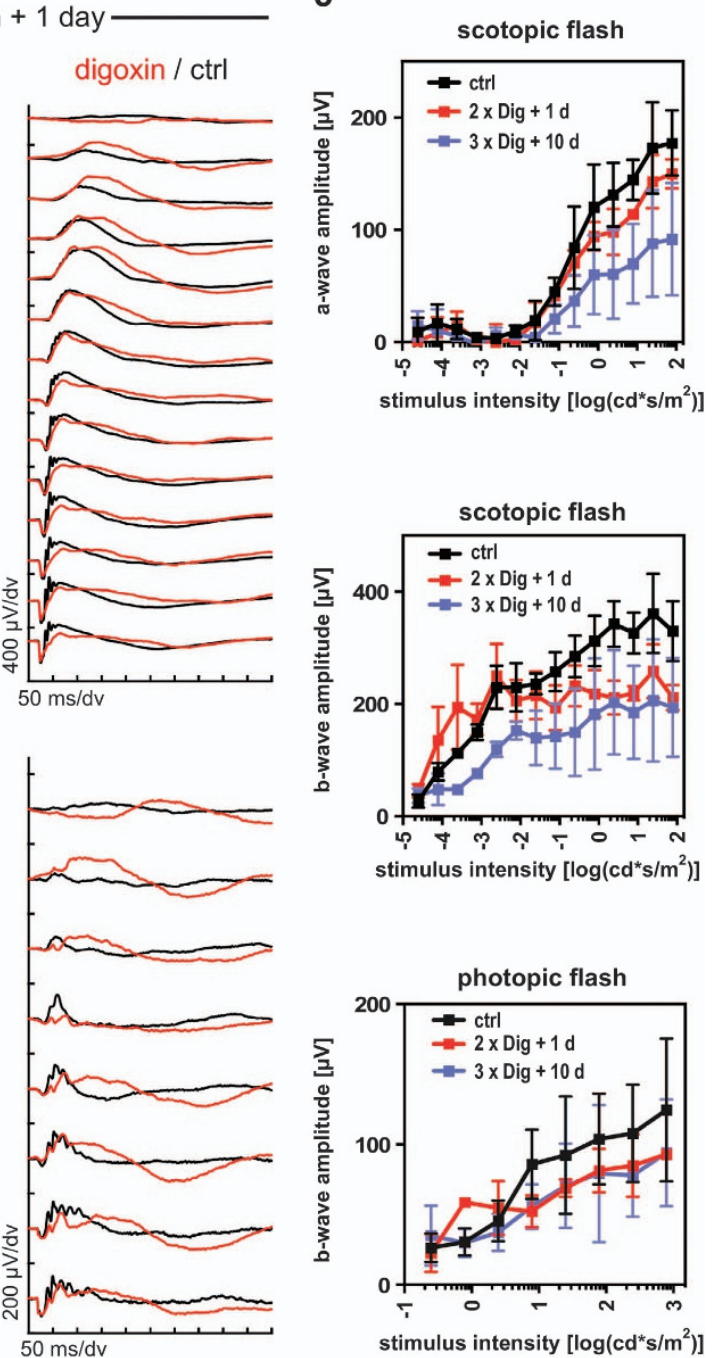

Figure 4 Retinal function after digoxin treatment. Mice received a toxic dose (three injections, $2 \mathrm{mg} / \mathrm{kg}$ each) or a subtoxic dose (two injections, $2 \mathrm{mg} / \mathrm{kg}$ each) of digoxin and were analyzed at 10 or 1 day after the last injection, as indicated. (a) Scotopic (top) and photopic (bottom) ERG traces were recorded from mice treated with the toxic digoxin dose ( $3 \times$ digoxin, blue lines). (b) Scotopic (top) and photopic (bottom) ERG traces were recorded from mice treated with the subtoxic digoxin dose ( $2 \times$ digoxin, red lines). ERGs were compared to mice injected twice with PBS (ctrl) and analyzed 1 day after the second injection (black lines in $\mathbf{a}$ and $\mathbf{b}$ ). Shown are traces averaged from $N=3$ mice (6 eyes). (c) Scotopic $a-$ and b-wave and photopic $b$-wave amplitudes plotted as a function of stimulus intensity. Shown are averages \pm S.D. $N=3$ mice ( 6 eyes). Color scheme as in (a and $\mathbf{b}$ )

degeneration in wild-type mice. Degeneration was restricted to photoreceptors of the central retina, depended on the presence of rhodopsin, activated stress signaling, and induced genes involved in degeneration, inflammation and oxidative stress. The dose needed to induce retinal degeneration was 100 to 1000 -fold higher than doses used to treat heart conditions in human patients. Indeed, reports indicate that patients treated with a daily dose of as little as few $\mu \mathrm{g} / \mathrm{kg}$ digoxin may occasionally experience blurred vision, dyschromatopsia and other visual symptoms as adverse effects. ${ }^{19}$ Whether treatment also cause some photoreceptor toxicity in patients has not been investigated as most disturbances seem reversible at the dose used in clinics. ${ }^{34}$ In mice, however, significantly higher doses are required for an effect since polymorphisms in murine Na,K-ATPases make mice profoundly more resistant to digoxin. $20,35,36$
Digoxin was recently shown to inhibit HIF1 in the model of oxygen-induced retinopathy $(\mathrm{OIR})^{31,32}$ and suppressed choroidal neovascularization (CNV) in a model of laser-induced lesions. ${ }^{32}$ Although both studies used wild-type mice, a digoxin concentration of $2 \mathrm{mg} / \mathrm{kg}$ (as used here) and repetitive intraperitoneal injections, no cytotoxic effects on photoreceptors were reported. The reason for this is unclear but may be based on the age of the mice during treatment. Both OIR studies injected digoxin between PND12 and PND17, at a time when retinal development has not yet been completed. In fact, photoreceptor function is very low at least up to PND16 ${ }^{37}$ suggesting that $\mathrm{Na}$,K-ATPases may not yet be fully functional at this time. Although Yoshida et al. ${ }^{32}$ also used adult mice in their model of laser-induced CNV, they analyzed treatment outcome in choroidal flat mounts focusing on neovascularization. A specific effect on photoreceptors was not investigated in their experiments. 

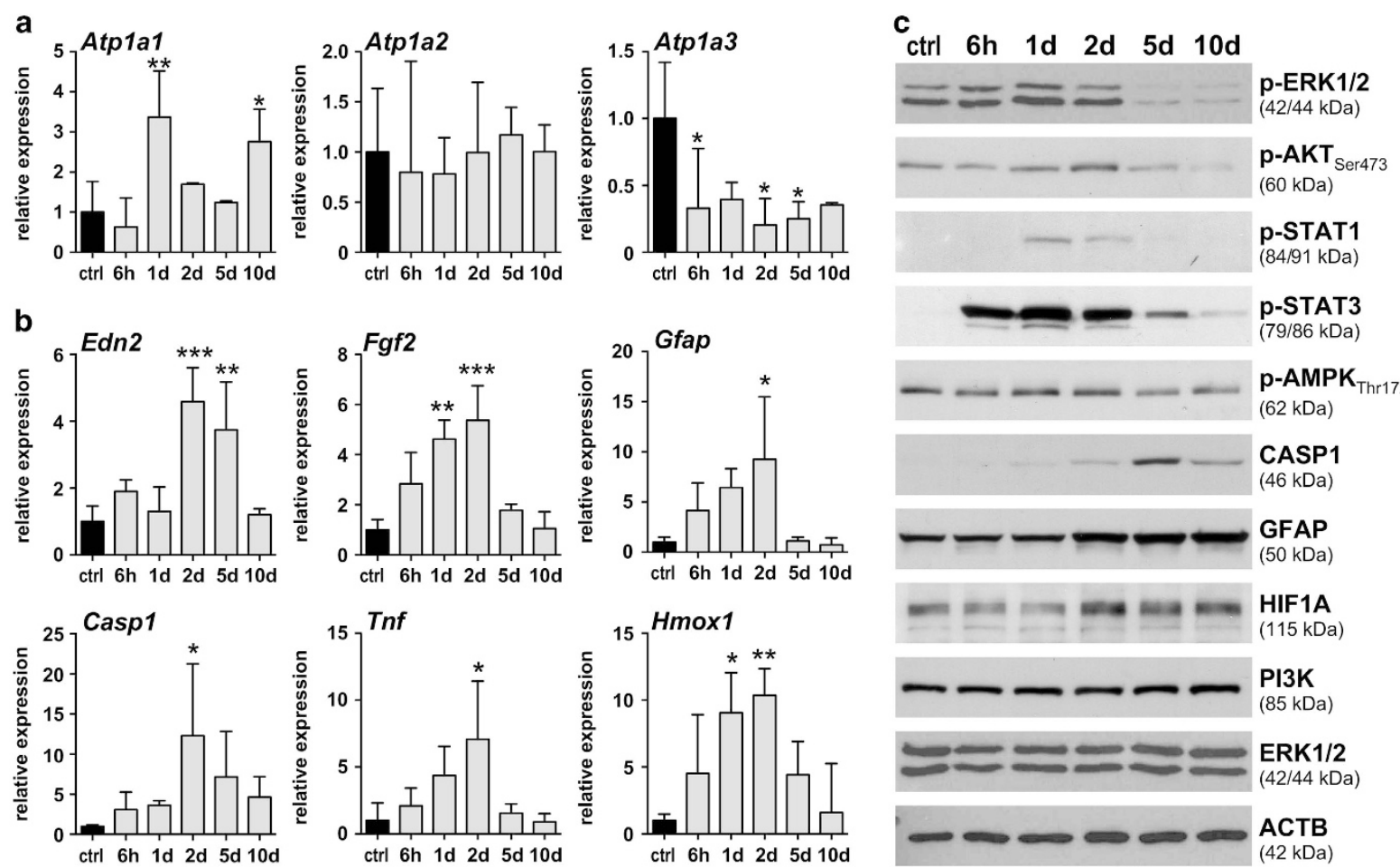

Figure 5 Retinal gene and protein expression after digoxin treatment. (a) Relative expression of genes encoding the alpha subunits of Na,K-ATPases. (b) Relative expression of genes involved in stress signaling and inflammation, as indicated. Retinal expression levels of digoxin-treated mice (gray bars) were normalized to Actb and expressed as fold change relatively to PBS-injected controls (ctrl, black bars, set to 1). Shown are means \pm S.D. of $N=3$. *: adjusted $P$-value $<0.05$. **: adjusted $P$-value $<0.01$. ${ }^{* * *}$ : adjusted $P$-value $<0.001$. One-way ANOVA with Dunnett's multiple comparison test (each column compared to control). (c) Retinal levels of selected proteins and phospho-proteins were tested by Western blotting. All analyses were done at five time points (as indicated) after the last of 3 injections of $2 \mathrm{mg} / \mathrm{kg}$ digoxin and compared to PBS-injected controls (ctrl). $N=3$

Digoxin inhibits primarily the catalytic alpha subunits of $\mathrm{Na}, \mathrm{K}-\mathrm{ATPases}{ }^{14}$ and has a certain selectivity for a2 and a3 isoforms ${ }^{7}$ that are also expressed in retinal cells including photoreceptors. ${ }^{17,38}$ As Na,K-ATPases are responsible for ion homeostasis and are critical for maintaining high extracellular levels of $\mathrm{Na}^{+}$and high intracellular $\mathrm{K}^{+},{ }^{39}$ inhibition of $\mathrm{Na}, \mathrm{K}-\mathrm{ATP}$ ase activity by digoxin leads to an increase in $\mathrm{Na}^{+}$ and a depletion of $\mathrm{K}^{+}$in the cells. ${ }^{39,40}$ As a consequence of high intracellular $\mathrm{Na}^{+}$, the entry-mode of the sodium/calcium exchanger (NCX) may be activated ${ }^{41}$ potentially causing increased intracellular $\mathrm{Ca}^{2+}$ levels in addition. ${ }^{42}$ Whereas a causative role of high intracellular $\mathrm{Na}^{+}$for the induction of cell death has not been established but may be connected to apoptosis through the regulation of cell volume, ${ }^{43} \mathrm{Ca}^{2+}$ has long been recognized as an important factor for the regulation of a variety of cellular processes including apoptosis. ${ }^{44} \mathrm{Ca}^{2+}$ may induce cell death, for example, through activation of calpains that leads to the proteolytic cleavage of intracellular substrates. ${ }^{45}$ Importantly, calpain-mediated cell death has also been reported in models of photoreceptor degeneration. ${ }^{46,47}$ Similarly, strong evidence suggests that depletion of intracellular $\mathrm{K}^{+}$is essential for the initiation of apoptosis in a variety of cells. ${ }^{48}$ The mechanisms that contribute to cell death by $\mathrm{K}^{+}$depletion are not known in detail, but may include regulation of cell volume, caspase activation and changes of the membrane potential of mitochondria. ${ }^{39}$ Loss of intracellular $\mathrm{K}^{+}$was directly implicated in photoreceptor degeneration in drosophila that lacked the alpha subunit of the Na,K-ATPase. ${ }^{49}$ Thus, inhibition of $\mathrm{Na}$,K-ATPases may alter intracellular ion homeostasis, which may significantly contribute to the degeneration of photoreceptor cells after digoxin application.

Increasing evidence suggests that $\mathrm{Na}, \mathrm{K}$-ATPases not only control cellular ion homeostasis but have also important functions in signal transduction ${ }^{50}$ by interacting with endogenous cardenolides including digoxin-like substances that are found in the circulation. ${ }^{51,52}$ Signaling may include activation of mitogen-activated protein kinases including ERK $1 / 2,{ }^{53}$ activation of PI3K and $\mathrm{AKT}^{29}$ and phosphorylation of SRC. ${ }^{54} \mathrm{Na}$,K-ATPases may thus constitute a class of cell surface receptors that can influence a number of physiological processes linked to cell survival in several cell types ${ }^{50}$ including neurons. ${ }^{55}$ We detected slight upregulation of pERK1/2 and pAKT at 1-2 days after digoxin injection. As digoxin has a half-life of $\sim 40 \mathrm{~h}$ in patients, ${ }^{56}$ it is likely that digoxin can still signal at this time point in mice. However, as ERK1/2 and AKT are also activated by degenerative processes, we cannot discriminate between a direct digoxinmediated effect and stress response signaling. It is interesting to note that both, pERK1/2 and pAMPK, levels drop below control levels late during the degenerative process. The reason for this is unclear but may signify the specific consequences of digoxin treatment. 


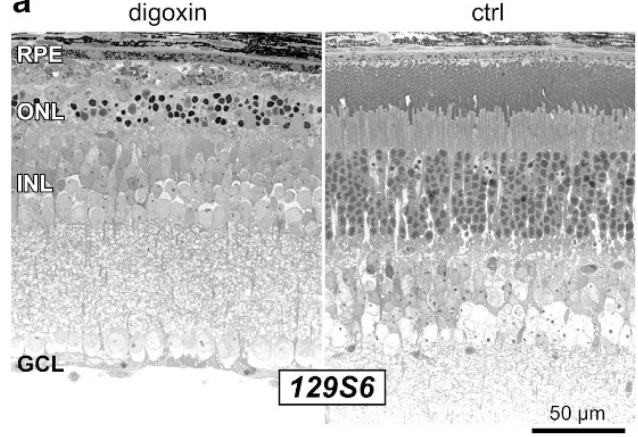

C

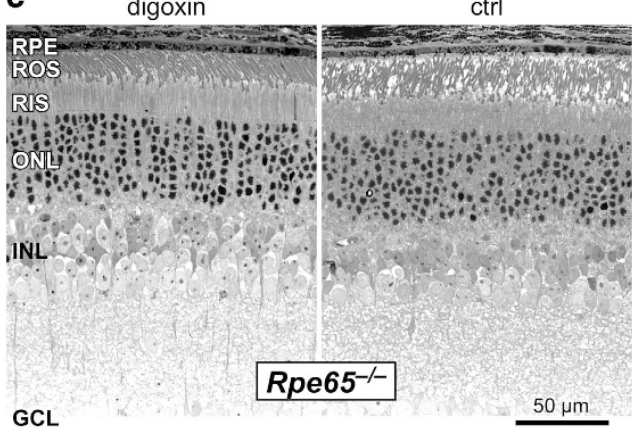

b

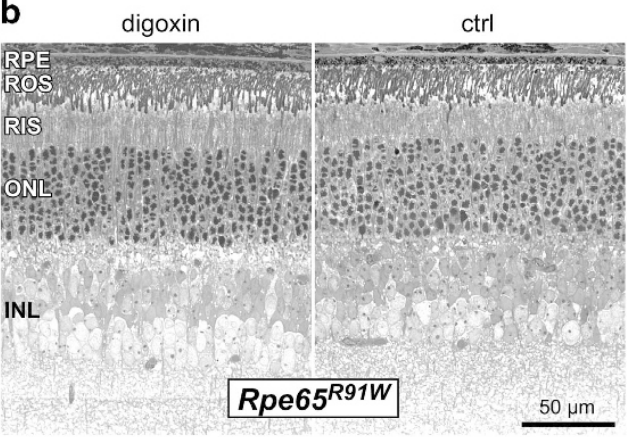

d digoxin ctrl

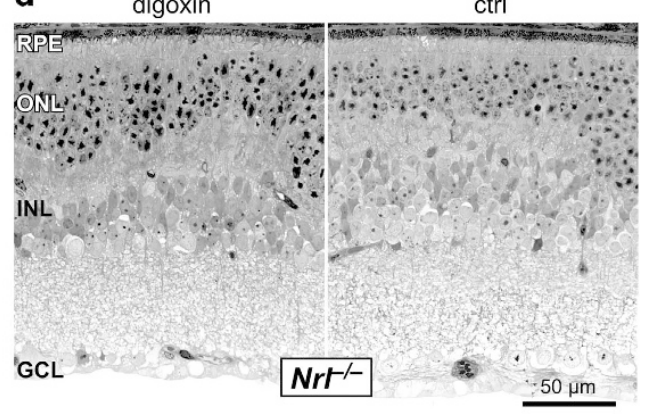

e
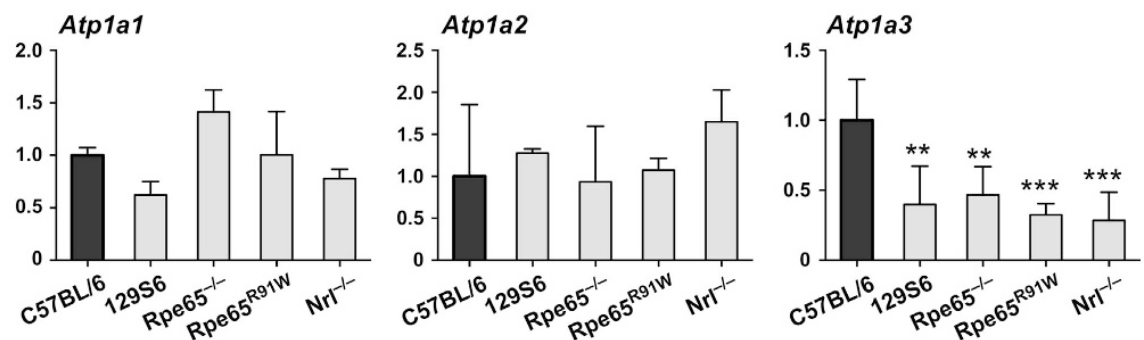

f
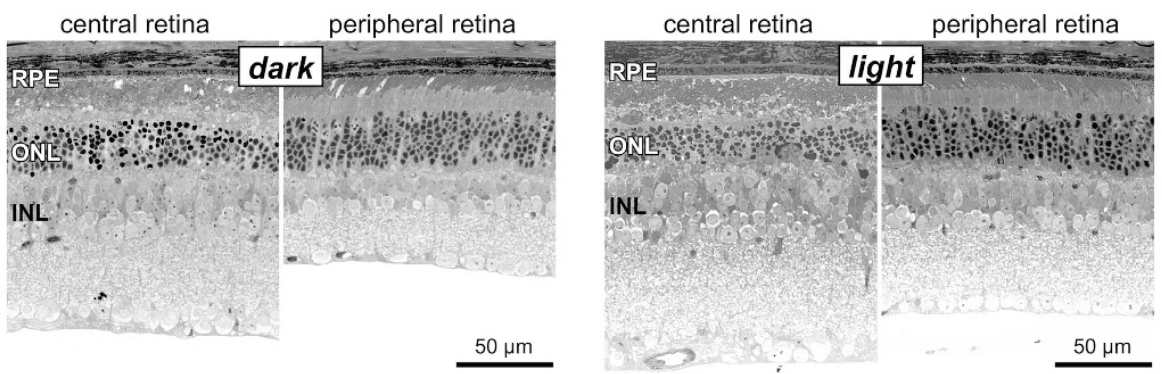

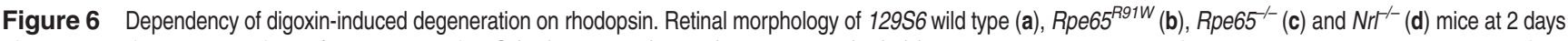
after the last of 3 injections of $2 \mathrm{mg} / \mathrm{kg}$ digoxin or of PBS (ctrl). $N=3-4$ (digoxin) and $N=2-4$ (ctrl). (e) Relative basal expression of Atp1a1, Atp1a2 and Atp1a3 in mice of the different strains as indicated. Expression levels were normalized to Actb and expressed relatively to levels in C57BL/6 mice (black bars, set to 1). Shown are means \pm S.D. of $N=3$. ${ }^{* *}$ : adjusted $P$-value $<0.01$. ${ }^{* * *}$ : adjusted $P$-value $<0.001 . N=3$. One-way ANOVA with Dunnett's multiple comparison test (each column compared to C57BL/6). (f) Retinal morphology of $129 \mathrm{~S} 6$ wild type at 2 days after the last of 3 injections of $2 \mathrm{mg} / \mathrm{kg}$ digoxin. Mice were either kept in darkness after the last injection according to the standard protocol (dark) or were exposed to a regular $12 \mathrm{~h} \mathrm{:} 12 \mathrm{~h}$ light-dark cycle (light, 60 lux during the light period). $N=3$. Ctrl, PBS-injected control mice; GCL, ganglion cell layer; INL, inner nuclear layer; ONL, outer nuclear layer; RPE, retinal pigment epithelium; ROS, rod outer segments; RIS, rod inner segments; Scale bars, $50 \mu \mathrm{m}$

Interestingly, photoreceptor degeneration caused by digoxin resembles light-induced retinal degeneration in several points. (i) degeneration is confined to photoreceptors ${ }^{57}$ (Figures 1 and 3); (ii) the central retina is more sensitive to damage ${ }^{57}$ (Figure 2); (iii) similar signaling pathways are activated ${ }^{58,59}$
(Figure 5); (iv) cones are less sensitive ${ }^{60}$ (Figure 6); and (v) degeneration depends on rhodopsin ${ }^{61,62}$ (Figure 6). The latter point is intriguing and not easily explained. Although hypotheses remain highly speculative, this result may indicate either an interaction of digoxin with rhodopsin inducing cytotoxicity 
Table 1 Primers used for real-time PCR

\begin{tabular}{|c|c|c|c|}
\hline Gene & Forward $5^{\prime}-3^{\prime}$ & Reverse $5^{\prime}-3^{\prime}$ & Product (bp) \\
\hline Actb & CAACGGCTCCGGCATGTGC & CTCTTGCTCTGGGCCTCG & 153 \\
\hline Atp1a1 & GGTGGTGCTCTCTGCTGTAG & GACGACATCCTCCGCATTGA & 161 \\
\hline Atp1a2 & CTGTCCTTGGATGAGCTGGG & CCTGAGCTCGCTGATTGGTG & 72 \\
\hline Atp1a3 & GAACTTCACCACAGACAACC & GACCATGATGACCTTGATGC & 121 \\
\hline Edn2 & AGACCTCCTCCGAAAGCTG & CTGGCTGTAGCTGGCAAAG & 64 \\
\hline Fgf2 & TGTGTCTATCAAGGGAGTGTGTGC & ACCAACTGGAGTATTTCCGTGACCG & 158 \\
\hline Casp1 & GGCAGGAATTCTGGAGCTTCAA & GTCAGTCCTGGAAATGTGCC & 138 \\
\hline Tnf & CCACGCTCTTCTGTCTACTGA & GGCCATAGAACTGATGAGAGG & 95 \\
\hline Hmox 1 & CCGCCTTCCTGCTCAACATT & GACGAAGTGACGCCATCTGTG & 99 \\
\hline Gfap & CCACCAAACTGGCTGATGTCTAC & TTCTCTCCAAATCCACACGAGC & 240 \\
\hline
\end{tabular}

by an unknown mechanism or an augmentation of digoxininduced cell stress by light absorption, for example by generating all-trans-retinal as a reactive aldehyde ${ }^{63}$ or reactive oxygen species. ${ }^{64}$ However, digoxin-induced degeneration did not notably differ between mice that were kept in darkness or exposed to normal cycling light after digoxin treatment (Figure 6f), making the first or an alternative explanation more likely. In any case, both light exposure and digoxin application cause altered intracellular ratios of $\mathrm{Na}^{+} / \mathrm{Ca}^{2+} / \mathrm{K}^{+}$through closure of the cGMP-gated channels or inhibition of $\mathrm{Na}, \mathrm{K}-\mathrm{ATPases}$, respectively. This leads to degenerative processes with several common features suggesting that maintenance of ion homeostasis is a crucial determinant of photoreceptor survival. Studying this model in more detail may shed light onto the regulation of ion homeostasis in connection to physiologic (signaling) and pathologic (degeneration) processes. This model may also provide an alternative to the induction of photoreceptor apoptosis by the highly toxic MNU that was used frequently to investigate cellular and molecular aspects of photoreceptor degeneration.

\begin{abstract}
Material and Methods
Mice and digoxin injections. All animal experimentation was performed in accordance to the ARVO Statement for the use of animals in ophthalmic and vision research and the regulations of the veterinary authorities of Zürich. C57BL/6 (wild type; Jackson lab, Sulzfeld, Germany), $129 S 6$ (wild type; Taconic, Ejby, Denmark), $\mathrm{Nr}^{-1-65} \mathrm{Rpe}^{-1-}$ (ref. 66) and Rpe65 ${ }^{\mathrm{R} 1 \mathrm{WW}}$ (ref. 33) mice were housed in the animal facility of the University of Zürich in a $12 \mathrm{~h}: 12 \mathrm{~h}$ light-dark cycle with access to food and water ad libitum. Three mice per strain and experimental condition were used at the age of 6-10 weeks, unless indicated otherwise.

Digoxin (Sigma, Buchs, Switzerland) was dissolved at a concentration of $40 \mathrm{mg} / \mathrm{mL}$ in DMSO, followed by dilution with PBS to $2 \mathrm{mg} / \mathrm{mL}$ and stored in aliquots at $-20{ }^{\circ} \mathrm{C}$. Immediately before use, digoxin was further diluted in PBS to $0.2 \mathrm{mg} / \mathrm{m}$ and injected intraperitoneally at doses ranging from $0.1 \mathrm{mg} / \mathrm{kg}$ to $2 \mathrm{mg} / \mathrm{kg}$. Injections were done once a day at 9-10 am for up to 3 consecutive days. Mice that were injected with PBS served as controls, except for Figure $2 b$ where uninjected mice were used as controls. During digoxin treatment, mice were housed in normal cages in $12 \mathrm{~h}: 12 \mathrm{~h}$ light-dark cycle (60 lux at cage level) with unrestricted access to food and water. After the last injection, mice were placed in darkness for 2 days before they were either killed or returned to the light-dark cycle until analysis. For the generation of data shown in Figure $6 f$ (light), mice were kept in the normal light-dark cycle for the entire duration of the experiment.
\end{abstract}

Morphology. Eyes were marked nasally, enucleated, fixed in glutaraldehyde (2.5\% in cacodylate buffer) over night at $4{ }^{\circ} \mathrm{C}$, trimmed, post-fixed in $1 \%$ osmium tetroxide and embedded in Epon 812 as described. ${ }^{67}$ Dorsoventral cross-sections of $0.5 \mu \mathrm{m}$ were cut through the optic nerve head, stained with toluidine blue and analyzed using light microscopy (Zeiss, Axioplan, Jena, Germany). Images of higher magnifications (Figures 1 and 6 ) were always acquired from the central region close to the optic nerve head, except where stated otherwise.

Immunofluorescence and TUNEL staining. Eyes were marked nasally, enucleated and prepared for cryosectioning essentially as described ${ }^{68}$ but without prior perfusion of the mice. Cryosections $(12 \mu \mathrm{m})$ were cut in a dorsoventral orientation, blocked for $1 \mathrm{~h}$ with blocking solution containing $3 \%$ normal goat serum (Sigma) and $0.3 \%$ Triton X-100 (Sigma) in PBS. Sections were incubated over night at $4{ }^{\circ} \mathrm{C}$ with the following primary antibodies: PNA-FITC (1:250, L7381, Sigma), rabbit anti-GNAT1 (1:500, sc-389, Santa Cruz Biotechnology; Santa Cruz, CA, USA), mouse anti-GFAP (1:250, G3893-Clone G-A-5, Sigma), rabbit anti-IBA1 (1:500, 019-19741, Wako, Neuss, Germany), mouse anti-POU4F1 (alias BRN3A; 1:100, MAB1585, Chemicon, Temecula, CA, USA), rabbit anti-VSX2 (alias CHX10; 1:500, kindly provided by Connie Cepko, Harvard University, MA, USA), mouse anti-CR (1:1000, AB5054, Chemicon) and rabbit anti-CALB1 (1:500, AB1778, Chemicon). Sections were washed with PBS, incubated for $1 \mathrm{~h}$ at room temperature with appropriate secondary antibodies labeled with Cy2 or Cy3 (Jackson ImmunoResearch Laboratories, Soham, UK), counterstained with 4',6'-diamidino-2-phenylindole (DAPI; Life Technologies, Zug, Switzerland) and analyzed using fluorescence microscopy (Zeiss).

For TUNEL staining, retinal cryosections were dried and fixed in 4\% PFA solution for $10 \mathrm{~min}$. After two washing steps with PBS (10 min each) a drop of $0.1 \%$ Triton $\mathrm{X}-100$ in $0.1 \%$ sodium citrate was added and incubated for $5 \mathrm{~min}$ for tissue permeabilization. After two washing steps with PBS (5 min each) sections were tested for TUNEL-positive signals using the in situ cell death detection kit (Roche Diagnostics, Rotkreuz, Switzerland) according to the manufacturer's instructions. Slides were mounted with Mowiol (Sigma), sealed with nail polish solution and analyzed by fluorescence microscopy. Images were always acquired from the central region close to the optic nerve head.

RNA isolation and semi-quantitative real-time PCR. Retinas were isolated through a slit in the cornea and snap frozen in liquid nitrogen. Retinal RNA was isolated using an RNA isolation kit according to the manufacturer's instructions (RNeasy, Qiagen, Hilden, Germany) with an additional on-column DNAse treatment to digest remaining genomic DNA. Concentration of eluted RNA was measured by Nanodrop spectrophotometer (Thermo Fisher Scientific, Waltham, MA, USA) and RNA diluted to a final concentration of $50 \mathrm{ng} / \mu \mathrm{l}$. cDNA was prepared from total RNA using oligo(dT) and M-MLV reverse transcriptase (Promega, Dübendorf, Switzerland). Semi-quantitative real-time PCR was performed in a LightCycler480 instrument (Roche Diagnostics) using the SYBR Green I master mix (Roche Diagnostics) and appropriate primer pairs (Table 1) designed to span large intronic regions and avoid known SNPs. Reactions were normalized to Actb and relative expression was calculated by the comparative threshold cycle method $\left(\Delta \Delta \mathrm{C}_{\mathrm{T}}\right)$ using the LightCycler480 software.

Protein isolation and Western blot. Retinas were isolated through a slit in the cornea and homogenized by sonication in $200 \mu \mathrm{l}$ of $100 \mathrm{mM} \mathrm{Tris} / \mathrm{HCl}(\mathrm{pH} 8,0)$. Homogenates were centrifuged ( $1000 \times \mathrm{g} ; 3 \mathrm{~min})$ and protein contents determined in the supernatants using Bradford reagent (Bio-Rad, Hercules, CA, USA). SDS-PAGE and Western blot analysis were performed as described ${ }^{67}$ using the following primary antibodies: rabbit anti-pERK (1:1000, \#9101, New England Biolabs, Herts, UK), rabbit anti-ERK (1 : 1000, \#9102, New England Biolabs), rabbit 
anti-pAKT Ser473 (1:1000, \#9271, Cell Signaling Technology, Danvers, MA, USA); rabbit anti-pSTAT1 $1_{\text {Tyr701 }}$ (1:500, \#9171, Cell Signaling Technology); rabbit

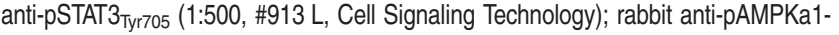
/2 ${ }_{\text {Thr172 }}$ (1:1000, sc-33524, Santa Cruz Biotechnology); rabbit anti-CASP1 (1:10 000, kindly provided by P. Vandenabeele, University of Gent, Gent, Belgium); mouse anti-GFAP (1:1000, G3893-Clone G-A-5, Sigma); rabbit anti-HIF-1 A (1:4000, NB100-479, Novus Biologicals, Cambridge, UK); rabbit anti-PI3K (1:4000, D0669, Upstate, Millipore, Darmstadt, Germany); mouse anti-ACTB (1:10,000, A5441, Sigma). Membranes were incubated with primary antibodies diluted (as indicated) in $5 \%$ non-fat blocking milk (Bio-Rad) in TBST over night at $4{ }^{\circ} \mathrm{C}$ with gentle agitation. After a 1-h incubation step with appropriate HRP-conjugated secondary antibodies, immunoreactive signals were detected using the Western lightning chemiluminescence reagent (PerkinEImer, Waltham, MA, USA). Signals were visualized using $\mathrm{X}$-ray films.

Electroretinography, fundus imaging and OCT. Mice were dark adaptated over night and pupils dilated using Cyclogyl 1\% (Alcon Pharmaceuticals, Fribourg, Switzerland) and Neosynephrine 5\% (Ursapharm Schweiz GmbH, Roggwil, Switzerland) $20 \mathrm{~min}$ before recording. Mice were anesthetized by a subcutaneous injection of ketamine (85 mg/kg, Parke-Davis, Berlin, Germany) and Xylazine (4 mg/kg, Bayer AG, Leverkusen, Germany). A drop of mydriacticum dispersa (OmniVision AG, Neuhausen, Switzerland) was applied to each cornea to induce mydriasis and to keep the tissue moist. Recordings were done using flashes of 13 different light intensities ranging from $-50 \mathrm{db}\left(0.000025 \mathrm{~cd}^{*} \mathrm{~s} / \mathrm{m}^{2}\right)$ to $15 \mathrm{db}$ $\left(79 \mathrm{~cd} / \mathrm{s}^{2} / \mathrm{m}^{2}\right)$ for scotopic and flashes of 8 different light intensities ranging from $-10 \mathrm{db}\left(25 \mathrm{~cd}^{*} \mathrm{~s} / \mathrm{m}^{2}\right)$ to $25 \mathrm{db}\left(790 \mathrm{~cd}^{*} \mathrm{~s} / \mathrm{m}^{2}\right)$ for photopic ERG as described. ${ }^{69}$ Ten recordings were averaged per light intensity.

Fundus imaging and OCT were done essentially as described. ${ }^{70}$ In brief, pupils of mice were dilated and mice anesthetized as describe as above. Eyes were kept moist with $2 \%$ methocel (OmniVision $A G$ ) and fundus images and OCT scans recorded using the Micron IV system (Phoenix Research Labs, Pleasanton, CA, USA).

Statistical analysis. Differences in gene expression levels were evaluated by one-way ANOVA followed by Dunnett's multiple comparison tests (GraphPad, San Diego, CA, USA) comparing all time points (Figures $5 a$ and b) or strains (Figure 6e) to the control or $\mathrm{C} 57 \mathrm{BL} / 6$, respectively.

\section{Conflict of Interest}

The authors declare no conflict of interest.

Acknowledgements. We thank Andrea Gubler and Cornelia Imsand for their excellent technical support and Mathias Seeliger (University of Tuebingen, Germany) for advice on ERG results. We also thank Connie Cepko and Peter Vandenabeele for kindly providing the Antibodies for VSX2 and Caspase 1. Supported by the Swiss National Science Foundation (SNF \#31003A_133043), the Cattaruzza Fonds and Pro Vista foundation.

1. Klein R, Klein BE, Knudtson MD, Meuer SM, Swift M, Gangnon RE. Fifteen-year cumulative incidence of age-related macular degeneration: the Beaver Dam Eye Study. Ophthalmology 2007; 114: 253-262.

2. Samardzija M, Neuhauss SCF, Joly S, Kurz-Levin M, Grimm C. Animal models for retinal degeneration. Animal Models for Retinal Diseases 2010; 46: 51-79.

3. Wenzel A, Grimm C, Samardzija M, Remé CE. Molecular mechanisms of light-induced photoreceptor apoptosis and neuroprotection for retinal degeneration. Prog Retin Eye Res 2005; 24: 275-306.

4. Yuge K, Nambu H, Senzaki H, Nakao I, Miki H, Uyama M et al. N-methyl-N-nitrosoureainduced photoreceptor apoptosis in the mouse retina. In Vivo 1996; 10: 483-488.

5. Ziff OJ, Kotecha D. Digoxin: the good and the bad. Trends Cardiovasc Med 2016; 26: $585-595$.

6. Prassas I, Karagiannis GS, Batruch I, Dimitromanolakis A, Datti A, Diamandis EP. Digitoxininduced cytotoxicity in cancer cells is mediated through distinct kinase and interferon signaling networks. Mol Cancer Ther 2011; 10: 2083-2093.

7. Katz A, Lifshitz Y, Bab-Dinitz E, Kapri-Pardes E, Goldshleger R, Tal DM et al. Selectivity of digitalis glycosides for isoforms of human Na,K-ATPase. J Biol Chem 2010; 285: 19582-19592.

8. Schoner W, Scheiner-Bobis G. Endogenous and exogenous cardiac glycosides and their mechanisms of action. Am J Cardiovasc Drugs 2007; 7: 173-189.

9. Lawrenson JG, Kelly C, Lawrenson AL, Birch J. Acquired colour vision deficiency in patients receiving digoxin maintenance therapy. Br J Ophthalmol 2002; 86: 1259-1261.
10. Kinoshita J, Iwata N, Kimotsuki $T$, Yasuda M. Digoxin-induced reversible dysfunction of the cone photoreceptors in monkeys. Invest Ophthalmol Vis Sci 2014; 55 881-892.

11. Morth JP, Pedersen BP, Buch-Pedersen MJ, Andersen JP, Vilsen B, Palmgren MG et al. A structural overview of the plasma membrane $\mathrm{Na}+, \mathrm{K}+-\mathrm{ATP}$ ase and $\mathrm{H}+$-ATPase ion pumps. Nat Rev Mol Cell Biol 2011; 12: 60-70.

12. Geering K. FXYD proteins: new regulators of Na-K-ATPase. Am J Physiol Renal Physiol 2006; 290: F241-F250.

13. Tokhtaeva $E$, Clifford RJ, Kaplan JH, Sachs G, Vagin O. Subunit isoform selectivity in assembly of Na,K-ATPase $\alpha-\beta$ heterodimers. J Biol Chem 2012; 287: 26115-26125.

14. Kaplan JH. Biochemistry of Na,K-ATPase. Annu Rev Biochem 2002; 71: 511-535.

15. Blanco G, Mercer RW. Isozymes of the Na-K-ATPase: heterogeneity in structure, diversity in function. Am J Physiol 1998; 275: F633-F650.

16. Blanco G. Na,K-ATPase subunit heterogeneity as a mechanism for tissue-specific ion regulation. Semin Nephrol 2005; 25: 292-303.

17. Wetzel RK, Arystarkhova E, Sweadner KJ. Cellular and subcellular specification of $\mathrm{Na}, \mathrm{K}$ ATPase alpha and beta isoforms in the postnatal development of mouse retina. J Neurosci 1999; 19: 9878-9889.

18. Jimenez T, McDermott JP, Sánchez G, Blanco G. Na,K-ATPase alpha4 isoform is essential for sperm fertility. Proc Natl Acad Sci USA 2011; 108: 644-649.

19. Renard D, Rubli E, Voide N, Borruat FX, Rothuizen LE. Spectrum of digoxin-induced ocular toxicity: a case report and literature review. BMC Res Notes 2015; 8: 368.

20. Hinshaw SJ, Ogbeifun O, Wandu WS, Lyu C, Shi G, Li Y et al. Digoxin inhibits induction of experimental autoimmune uveitis in mice, but causes severe retinal degeneration. Invest Ophthalmol Vis Sci 2016; 57: 1441-1447.

21. Jehle T, Wingert K, Dimitriu C, Meschede W, Lasseck J, Bach M et al. Quantification of ischemic damage in the rat retina: a comparative study using evoked potentials, electroretinography, and histology. Invest Ophthalmol Vis Sci 2008; 49: 1056-1064.

22. Pournaras CJ, Rungger-Brändle E, Riva CE, Hardarson SH, Stefansson E. Regulation of retinal blood flow in health and disease. Prog Retin Eye Res 2008; 27: 284-330.

23. Dobre D, Borer JS, Fox K, Swedberg K, Adams KF, Cleland JG et al. Heart rate: a prognostic factor and therapeutic target in chronic heart failure. The distinct roles of drugs with heart rate-lowering properties. Eur J Heart Fail 2014; 16: 76-85.

24. Longhurst JC, Ross J. Extracardiac and coronary vascular effects of digitalis. J Am Coll Cardiol 1985; 5: 99 A-105 A

25. Li Z, Xie Z. The Na/K-ATPase/Src complex and cardiotonic steroid-activated protein kinase cascades. Pflugers Arch 2009; 457: 635-644.

26. Katz A, Tal DM, Heller D, Habeck M, Ben Zeev E, Rabah B et al. Digoxin derivatives with selectivity for the $\alpha 2 \beta 3$ isoform of Na,K-ATPase potently reduce intraocular pressure. Proc Natl Acad Sci USA 2015; 112: 13723-13728.

27. Wang Y, Qiu Q, Shen JJ, Li DD, Jiang XJ, Si SY et al. Cardiac glycosides induce autophagy in human non-small cell lung cancer cells through regulation of dual signaling pathways. Int J Biochem Cell Biol 2012; 44: 1813-1824.

28. Samardzija M, Wenzel A, Thiersch M, Frigg R, Remé C, Grimm C. Caspase-1 ablation protects photoreceptors in a model of autosomal dominant retinitis pigmentosa. Invest Ophthalmol Vis Sci 2006; 47: 5181-5190.

29. Liu L, Zhao X, Pierre SV, Askari A. Association of PI3K-Akt signaling pathway with digitalisinduced hypertrophy of cardiac myocytes. Am J Physiol Cell Physiol 2007; 293: C1489-C1497.

30. Liu L, Ivanov AV, Gable ME, Jolivel F, Morrill GA, Askari A. Comparative properties of caveolar and noncaveolar preparations of kidney Na+/K+-ATPase. Biochemistry 2011; 50: 8664-8673.

31. Xin X, Rodrigues M, Umapathi M, Kashiwabuchi F, Ma T, Babapoor-Farrokhran $S$ et al. Hypoxic retinal Muller cells promote vascular permeability by HIF-1-dependent up-regulation of angiopoietin-like 4. Proc Natl Acad Sci USA 2013; 110: E3425-E3434.

32. Yoshida T, Zhang H, Iwase T, Shen J, Semenza GL, Campochiaro PA. Digoxin inhibits retinal ischemia-induced HIF-1alpha expression and ocular neovascularization. FASEB J 2010; 24: 1759-1767.

33. Samardzija M, von Lintig J, Tanimoto N, Oberhauser V, Thiersch M, Remé CE et al. R91W mutation in Rpe65 leads to milder early-onset retinal dystrophy due to the generation of low levels of 11-cis-retinal. Hum Mol Genet 2008; 17: 281-292.

34. Weleber RG, Shults WT. Digoxin retinal toxicity. Clinical and electrophysiological evaluation of a cone dysfunction syndrome. Arch Ophthalmol 1981; 99: 1568-1572.

35. Beheshti Zavareh R, Lau KS, Hurren R, Datti A, Ashline DJ, Gronda M et al. Inhibition of the sodium/potassium ATPase impairs N-glycan expression and function. Cancer Res 2008; 68: 6688-6697.

36. Price EM, Lingrel JB. Structure-function relationships in the Na,K-ATPase alpha subunit: site-directed mutagenesis of glutamine-111 to arginine and asparagine-122 to aspartic acid generates a ouabain-resistant enzyme. Biochemistry 1988; 27: 8400-8408.

37. Gibson R, Fletcher EL, Vingrys AJ, Zhu Y, Vessey KA, Kalloniatis M. Functional and neurochemical development in the normal and degenerating mouse retina. J Comp Neurol 2013: 521: 1251-1267.

38. Maturana-Teixeira S, Braga LE, Carpi Santos R, Calaza KC, Giestal-de-Araujo E, Leão-Ferreira LR. The $(\mathrm{Na}(+) / \mathrm{K}(+))$-ATPase activity in the developing rat retina: the role of insulin-like growth factor-I (IGF-I). Cell Mol Neurobiol 2015; 35: 243-254.

39. Yu SP. $\mathrm{Na}(+), \mathrm{K}(+)-$-ATPase: the new face of an old player in pathogenesis and apoptotic/ hybrid cell death. Biochem Pharmacol 2003; 66: 1601-1609. 
40. Archibald JT, White TD. Rapid reversal of internal $\mathrm{Na}+$ and $\mathrm{K}+$ contents of synaptosomes by ouabain. Nature 1974; 252: 595-596.

41. Blaustein MP, Lederer WJ. Sodium/calcium exchange: its physiological implications. Physiol Rev 1999; 79: 763-854.

42. Kamimura D, Ohtani T, Sakata Y, Mano T, Takeda Y, Tamaki S et al. Ca2+ entry mode of $\mathrm{Na}$ $+/ \mathrm{Ca} 2+$ exchanger as a new therapeutic target for heart failure with preserved ejection fraction. Eur Heart J 2012; 33: 1408-1416.

43. Bortner CD, Cidlowski JA. Uncoupling cell shrinkage from apoptosis reveals that $\mathrm{Na}+$ influx is required for volume loss during programmed cell death. J Biol Chem 2003; 278 : 39176-39184.

44. Pinton P, Giorgi C, Siviero R, Zecchini E, Rizzuto R. Calcium and apoptosis: ER-mitochondria $\mathrm{Ca} 2+$ transfer in the control of apoptosis. Oncogene 2008; 27 : 6407-6418.

45. Storr SJ, Carragher NO, Frame MC, Parr T, Martin SG. The calpain system and cancer. Nat Rev Cancer 2011; 11: 364-374.

46. Imai S, Shimazawa M, Nakanishi T, Tsuruma K, Hara H. Calpain inhibitor protects cells against light-induced retinal degeneration. J Pharmacol Exp Ther 2010; 335: 645-652.

47. Sharma AK, Rohrer B. Sustained elevation of intracellular cGMP causes oxidative stress triggering calpain-mediated apoptosis in photoreceptor degeneration. Curr Eye Res 2007; 32: 259-269.

48. Yu SP. Regulation and critical role of potassium homeostasis in apoptosis. Prog Neurobiol 2003; 70: 363-386.

49. Luan Z, Reddig K, Li HS. Loss of $\mathrm{Na}(+) / \mathrm{K}(+)$-ATPase in Drosophila photoreceptors leads to blindness and age-dependent neurodegeneration. Exp Neurol 2014; 261: 791-801.

50. Aperia A, Akkuratov EE, Fontana JM, Brismar H. Na+-K+-ATPase, a new class of plasma membrane receptors. Am J Physiol Cell Physiol 2016; 310: C491-C495.

51. Bagrov AY, Shapiro Jl, Fedorova OV. Endogenous cardiotonic steroids: physiology, pharmacology, and novel therapeutic targets. Pharmacol Rev 2009; 61: 9-38.

52. Brar KS, Gao Y, El-Mallakh RS. Are endogenous cardenolides controlled by atrial natriuretic peptide. Med Hypotheses 2016; 92: 21-25.

53. Mohammadi K, Kometiani $\mathrm{P}$, Xie Z, Askari A. Role of protein kinase $\mathrm{C}$ in the signal pathways that link Na+/K+-ATPase to ERK1/2. J Biol Chem 2001; 276: 42050-42056.

54. Haas M, Askari A, Xie Z. Involvement of Src and epidermal growth factor receptor in the signal-transducing function of Na+/K+-ATPase. J Biol Chem 2000; 275: 27832-27837.

55. Sibarov DA, Bolshakov AE, Abushik PA, Krivoi II, Antonov SM. Na+,K+-ATPase functionally interacts with the plasma membrane $\mathrm{Na}+, \mathrm{Ca} 2+$ exchanger to prevent $\mathrm{Ca} 2+$ overload and neuronal apoptosis in excitotoxic stress. J Pharmacol Exp Ther 2012; 343: 596-607.

56. Chan BS, Buckley NA. Digoxin-specific antibody fragments in the treatment of digoxin toxicity. Clin Toxicol (Phila) 2014; 52: 824-836.

57. Remé CE, Grimm C, Hafezi F, Marti A, Wenzel A. Apoptotic cell death in retinal degenerations. Prog Retin Eye Res 1998; 17: 443-464.

58. Samardzija M, Wenzel A, Aufenberg S, Thiersch M, Remé C, Grimm C. Differential role of Jak-STAT signaling in retinal degenerations. FASEB J 2006; 20: 2411-2413.

59. Joly S, Lange C, Thiersch M, Samardzija M, Grimm C. Leukemia inhibitory factor extends the lifespan of injured photoreceptors in vivo. J Neurosci 2008; 28: 13765-13774.
60. Okano K, Maeda A, Chen Y, Chauhan V, Tang J, Palczewska G et al. Retinal cone and rod photoreceptor cells exhibit differential susceptibility to light-induced damage. J Neurochem 2012; 121: 146-156.

61. Grimm C, Wenzel A, Hafezi F, Yu S, Redmond TM, Remé CE. Protection of Rpe65-deficient mice identifies rhodopsin as a mediator of light-induced retinal degeneration. Nat Genet 2000; 25: 63-66.

62. Wenzel A, Grimm C, Samardzija M, Remé CE. The genetic modifier Rpe65Leu(450): effect on light damage susceptibility in c-Fos-deficient mice. Invest Ophthalmol Vis Sci 2003; 44: 2798-2802.

63. Maeda T, Golczak M, Maeda A. Retinal photodamage mediated by all-trans-retinal. Photochem Photobiol 2012; 88: 1309-1319.

64. Organisciak DT, Vaughan DK. Retinal light damage: mechanisms and protection. Prog Retin Eye Res 2010; 29: 113-134.

65. Mears AJ, Kondo M, Swain PK, Takada Y, Bush RA, Saunders TL et al. Nrl is required for rod photoreceptor development. Nat Genet 2001; 29: 447-452.

66. Redmond TM, Yu S, Lee E, Bok D, Hamasaki D, Chen N et al. Rpe65 is necessary for production of 11-cis-vitamin A in the retinal visual cycle. Nat Genet 1998; 20: 344-351.

67. Heynen SR, Tanimoto N, Joly S, Seeliger MW, Samardzija M, Grimm C. Retinal degeneration modulates intracellular localization of CDC42 in photoreceptors. Mol Vis 2011; 17: 2934-2946.

68. Joly S, Samardzija M, Wenzel A, Thiersch M, Grimm C. Nonessential role of beta3 and beta5 integrin subunits for efficient clearance of cellular debris after light-induced photoreceptor degeneration. Invest Ophthalmol Vis Sci 2009; 50: 1423-1432.

69. Kast B, Schori C, Grimm C. Hypoxic preconditioning protects photoreceptors against light damage independently of hypoxia inducible transcription factors in rods. Exp Eye Res 2016; 146: $60-71$.

70. Geiger P, Barben M, Grimm C, Samardzija M. Blue light-induced retinal lesions, intraretinal vascular leakage and edema formation in the all-cone mouse retina. Cell Death Dis 2015; 6 : e1985.

(i) Cell Death and Disease is an open-access journal published by Nature Publishing Group. This work is licensed under a Creative Commons Attribution 4.0 International License. The images or other third party material in this article are included in the article's Creative Commons license, unless indicated otherwise in the credit line; if the material is not included under the Creative Commons license, users will need to obtain permission from the license holder to reproduce the material. To view a copy of this license, visit http://creativecommons.org/licenses/by/4.0/

(C) The Author(s) 2017 